\title{
БИОЛЮМИНЕСЦЕНТНЫЙ ИМИДЖИНГ: НОВЫЕ ВОЗМОЖНОСТИ
}

\author{
3. М. Осипова ${ }^{1,2}$, А. С. Щеглов ${ }^{1,2} \bowtie$, И. В. Ямпольский ${ }^{1,2}$ \\ ${ }^{1}$ Отдел биомолекулярной химии, Институт биоорганической химии имени М. М. Шемякина и Ю. А. Овчинникова РАН, Москва \\ 2 Лаборатория химии природных соединений, Российский национальный исследовательский медицинский университет имени Н. И. Пирогова, Москва
}

\begin{abstract}
Современные биомедицинские исследования активно используют методы биоимиджинга клеток, тканей и целых организмов. Многоцветный биоимиджинг находит свое применение в случае необходимости одновременного наблюдения разных событий на молекулярном и клеточном уровнях. Наиболее чувствительными являются методы биолюминесцентного имиджинга, однако их использование для многоцветного мечения сдерживается недостаточным количеством доступных пар люцифераза-люциферин. Удачным расширением палитры инструментов молекулярного имиджинга могут стать новые биолюминесцентные системы высших грибов и морской полихеты Odontosyllis, обладающие рядом преимуществ по сравнению с ранее изученными системами.
\end{abstract}

Ключевые слова: биолюминесценция, биоимиджинг, люциферин, люцифераза

Финансирование: работа выполнена при финансовой поддержке Министерства высшего образования и науки РФ в рамках реализации федеральной целевой программы «Исследования и разработки по приоритетным направлениям развития научно-технологического комплекса России на $2014-2020$ годы», Соглашение № 14.613.21.0062, идентификатор проекта RFMEFI61317X0062.

$\triangle$ Для корреспонденции: Александр Сергеевич Щеглов ул. Миклухо-Маклая, 16/10, г. Москва, 117997; jukart@mail.ru

Статья получена: 02.11.2018 Статья принята к печати: 19.11.2018

DOI: 10.24075/vrgmu.2018.063

\section{BIOLUMINESCENT IMAGING: NEW OPPORTUNITIES}

Osipova ZM ${ }^{1,2}$, Shcheglov AS ${ }^{1,2}$, Yampolsky IV ${ }^{1,2}$

Biomolecular Chemistry Department, Shemyakin-Ovchinnikov Institute of Bioorganic Chemistry of the Russian Academy of Sciences, Moscow

${ }^{2}$ Laboratory of Natural Compounds Chemistry, Pirogov Russian National Research Medical University, Moscow

Modern biomedical research technologies actively use bioimaging for studying cells, tissues and whole organisms. Multicolor bioimaging is applied when simultaneous observation of different events at the molecular and cellular level is needed. Bioluminescent imaging methods are the most sensitive, however, their use for multicolor labeling is complicated due to the insufficient number of available uciferin-luciferase pairs. Having a number of advantages compared to previously studied bioluminescent systems, the new bioluminescence systems of higher fungi and marine polychaete Odontosyllis could become a useful expansion of the bioimaging toolbox.

Keywords: bioluminescence, bioimaging, luciferin, luciferase

Funding: the study was funded by the Ministry of Science and Higher Education of the Russian Federation under the Federal Targeted Programme for Research and Development in Priority Areas of Development of the Russian Scientific and Technological Complex for 2014-2020, Agreement \#14.613.21.0062, project identifier RFMEFI61317X0062.

$\square$ Correspondence should be addressed: Alexander S. Shcheglov

Miklukho-Maklaya 16/10, Moscow, 117997; jukart@mail.ru

Received: 02.11.2018 Accepted: 19.11.2018

DOI: $10.24075 /$ brsmu.2018.063

Современные исследования молекулярных событий при изучении развития заболеваний не обходятся без биоимиджинга тканей и целых организмов [1]. В биоимиджинге очень популярно применение флуоресцентных и биолюминесцентных белков (люцифераз). Для флуоресцентного биоимиджинга разработан набор флуоресцентных белков с различными спектральными свойствами - от фиолетовых до дальне-красных, фотоактивируемые и фотопереключаемые белки, а также сенсоры на их основе [2]. Доступных для биоимиджинга люцифераз существенно меньше, чем флуоресцентных белков, однако методы, созданные на основе биолюминесценции, относятся к самым чувствительным для проведения исследований в глубоких тканях.

Люцифераза катализирует свечение в результате реакции окисления молекулярного субстрата люциферина, поэтому для получения аналитического сигнала, в отличие от флуоресцентного белка, внешний источник излучения не требуется. В связи с этим биолюминесцентный имиджинг in vivo фактически не имеет фоновых помех и обладает беспрецедентной чувствительностью [3]. Однако использование люцифераз в качестве репортерных белков не лишено недостатков. Так, активность некоторых из них сильно зависит от количества кофакторов либо ингибируется внутриклеточными компонентами или лекарственными препаратами [4]. И несмотря на то что применение биолюминесцентых систем менее удобно в практическом смысле, так как для световой эмиссии необходимо как минимум два компонента, а не один, эта область продолжает бурно развиваться.

\section{Инструменты для биолюминесцентного имиджинга}

Многоцветный биоимиджинг находит свое применение в случае необходимости одновременного наблюдения разных событий на молекулярном уровне (например, экспрессии генов или белок-белковых взаимодействий), позволяя сократить количество используемых в эксперименте 
животных. При этом возможны разные стратегии. Вот некоторые из них: совместное использование люцифераз разных организмов, мутантных люцифераз одного организма, применение гибридных белковых конструкций «люцифераза-флуоресцентный белок» и др. [5].

Среди наиболее популярных люцифераз для биоимиджинга - люциферазы Fluc североамериканского светляка Photinus pyralis (62 кДа), жука-щелкуна Pyrophorus plagiophthalamus (62 кДа) $\left(\lambda_{\max } \approx 540-615 \mathrm{Hm}\right.$ ) и люциферазы морских организмов Renilla reniformis Rluc (36 кДа) и Gaussia princeps Gluc (20 кДа) ( $\left.\lambda_{\max } \approx 480 \mathrm{нм}\right)$ [6]. Люциферазы почвенных организмов катализируют реакцию D-люциферина с кислородом в присутствии кофакторов АТФ и ионов $\mathrm{Mg}^{2+}$, морские люциферазы работают совместно с люциферином целентеразином. С 2012 г. уникальную популярность приобрела инженерная люцифераза NanoLuc (19 kДа) $\left(\lambda_{\max }=460 \mathrm{Hм}\right)$, разработанная на основе малого домена люциферазь Oplophorus gracilirostris [7]. Для NanoLuc используется другой субстрат - синтетический аналог целентеразина фуримазин.

Популярность люцифераз, работающих с D-люциферином, обусловлена не только исторически, но и по причине того, что данная система пригодна для имиджинга процессов, в которых участвует молекула АТФ [8]. Кроме того, для $D$-люциферина было разработано широкое разнообразие структурных аналогов [3], в том числе испускающих свет в более красной области спектра, например недавно предложенный AkaLumine- $\mathrm{HCl}\left(\lambda_{\max }=677 \mathrm{HM}\right)$ [9]. Здесь необходимо пояснить, что смещение спектра излучения биолюминесценции в сторону ближней ИКобласти значимо, поскольку эта область является окном прозрачности для изучения процессов в глубоких тканях in vivo. Помимо улучшенных спектральных характеристик достоинство аналога AkaLumine- $\mathrm{HCl}$ заключается в более удачном биораспределении в клетках глубоких тканей и более эффективном, чем в случае $D$-люциферина, насыщении светляковой люциферазы Fluc. Направленный мутагенез Fluc привел к получению искусственной люциферазы Akaluc, более активной с синтетическим субстратом, чем природная [10]. Разработанная система AlaBLI почти в 100-1000 раз ярче, чем существующие, и пригодна для биоимиджинга отдельных клеток в глубоких тканях свободно движущихся животных.

Технологически осуществить одновременный анализ сигналов от разных процессов можно с помощью светового фильтра при совместном применении разных биолюминесцентных систем (например, в стандартном Promega DLR assay используют $P$. pyralis и $R$. reniformis) либо при использовании нескольких мутантных белков в рамках одной биолюминесцентной системы. В качестве примера последнего можно привести недавно предложенный метод DART, в котором применяются зеленый (PLG) и красный (PLR1) мутанты люциферазы светляка совместно c D-люциферином и его бензотиофеновым аналогом соответственно [11]. Недостатком указанных методов является ингибирование светового сигнала люциферазами в первом случае либо возможные перекрестные реакции родственных люцифераз с аналогичными субстратами во втором.

По аналогии с упомянутой выше системой AlaBLI, интересным подходом к преодолению существующих недостатков является разработка полностью искусственных люцифераз, работающих со стандартными субстратами на основе генетических последовательностей уже известных белков, например полученная недавно серия Aluc, представители которой работают с целентеразином и аналогами $\left(\lambda_{\max }=487-500\right.$ нм) [12]. Химическая модификация целентеразина путем конъюгации с флуоресцентными красителями позволила сместить максимум эмиссии в реакции с Aluc в еще более длинноволновую область [13]. Близкий по идее подход через предварительные расчеты выявил несколько ортогональных пар «аналог D-люциферина - мутантная люцифераза Fluc», для которых активность была подтверждена in vivo [14].

Удобство применения люцифераз морских организмов обусловлено, в первую очередь, отсутствием кофакторов в реакции люминесценции, что существенно упрощает анализ и позволяет использовать их для имиджинга вне живой клетки. Особенно популярной стала специально полученная люцифераза NanoLuc. Еe миниатюрные размеры упрощают разработку новых гибридных белков «люцифераза - флуоресцентный белок», используемых для расширения имиджинговой палитры с помощью BRET. Феномен BRET основан на Ферстеровском резонансном переносе энергии (FRET) от люциферазы к фллуоресцентному белку, в результате чего максимум эмиссии оказывается в смещенном диапазоне. Из люциферазы NanoLuc и соответствующих белков была создана целая палитра химерных белков, в которых с помощью разных флуорофоров максимум эмиссии сдвинут вплоть до 680 нм [15]. В качестве аналогичного примера можно упомянуть недавно разработанные химерные белки Rluc8-iRFPs, также работающие в длинноволновой области [16].

\section{Расширение палитры: новые люминесцентные системь}

Для решения задачи расширения доступной биолюминесцентной палитры не менее перспективен подход по изучению новых, ранее не исследованных люминесцентных систем. Например, не так давно были установлены структуры люциферинов почвенного червя Fridericia heliota $\left(\lambda_{\text {max }}=480\right.$ нм) и люциферина грибов $\left(\lambda_{\max }=530\right.$ нм) [3]. Для последнего уже получена рекомбинантная люцифераза [17]. Себестоимость люциферина грибов в десятки раз ниже, чем самого популярного $D$-люциферина, а стабильность его намного выше. Принципиальная возможность легко модифицировать структуру люциферина и получать функциональные аналоги, испускающие свет в более длинноволновом диапазоне [18], делает новую биолюминесцентную систему грибов весьма привлекательной для использования в биоимиджинге. Некоторым осложнением могут стать необходимость участия косакторов в реакции и мембранная локализация люциферазы грибов.

В 2018 г. была выделена люцисераза морской полихеты Odontosyllis undecimonta [19]. Данный белок не проявляет люминесцентную активность с уже известными люциферинами морских организмов (целентеразин, люцисерин Cypridina). Таким образом, впервые за долгое время охарактеризована люцифераза морского организма, относящаяся К принципиально новому типу биолюминесцентной системы, т. е. ортогональная всем изученным ранее. Максимум биолюминесценции Odontosyllis in vivo находится в области 510 нм. Реакция между люциферином и люциферазой Odontosyllis так же, как и в случае других морских люминесцентных систем, не требует участия кофакторов. Как только будет 
расшифрована структура люциферина Odontosyllis и разработан метод его синтеза, эта биолюминесцентная система будет активно применяться в биоимиджинге.

\section{ВЫВОДЫ}

Огромное разнообразие методов многоцветного биоимиджинга позволяет выбрать оптимальный для решения конкретной задачи в медицинском исследовании.
Наиболее чувствительны методы биолюминесцентного имиджинга, однако их использование для многоцветного мечения сдерживается недостаточным количеством доступных пар люцифераза-люциферин. Удачным расширением палитры инструментов могут стать недавно изученные биолюминесцентные системы высших грибов и морской полихеты Odontosyllis, обладающие рядом преимуществ по сравнению с теми, которые популярны на данный момент.

\section{Литература}

1. Cevenini L, Camarda G, Michelini E, Siciliano G, Calabretta MM, Bona R, Kumar TS, Cara A, Branchini BR, Fidock DA, Roda A. Multicolor bioluminescence boosts malaria research: quantitative dual-color assay and single-cell imaging in Plasmodium falciparum parasites. Anal Chem. 2014; 15; 86 (17): 8814-21.

2. Chudakov DM, Matz MV, Lukyanov S, Lukyanov KA. Fluorescent proteins and their applications in imaging living cells and tissues. Physiol Rev. 2010 Jul; 90 (3): 1103-63.

3. Kaskova ZM, Tsarkova AS, Yampolsky IV. 1001 lights: luciferins, luciferases, their mechanisms of action and applications in chemical analysis, biology and medicine. Chem Soc Rev. 2016; 45 (21): 6048-77.

4. Nakajima Y, Ohmiya Y. Bioluminescence assays: multicolor luciferase assay, secreted luciferase assay and imaging luciferase assay. Expert Opin Drug Discov. 2010; 5 (9): 835-49.

5. Yao Z, Zhang BS, Prescher JA. Advances in bioluminescence imaging: new probes from old recipes. Curr Opin Chem Biol. 2018; 45: 148-56.

6. Shimomura O. Bioluminescence: chemical principles and methods. Singapore: World Scientific; 2012.

7. Hall MP, Unch J, Binkowski BF, Valley MP, Butler BL, Wood MG, Otto P, Zimmerman K, Vidugiris G, Machleidt T, Robers MB. Engineered luciferase reporter from a deep sea shrimp utilizing a novel imidazopyrazinone substrate. ACS Chem Biol. 2012; 7 (11): 1848-57.

8. Rajendran M, Dane E, Conley J, Tantama M. Imaging adenosine triphosphate (ATP). Biol Bull. 2016; 231 (1): 73-84.

9. Kuchimaru T, Iwano S, Kiyama M, Mitsumata S, Kadonosono T, Niwa H, Maki S, Kizaka-Kondoh S. A luciferin analogue generating near-infrared bioluminescence achieves highly sensitive deeptissue imaging. Nat Commun. 2016; 7: 11856.

10. Iwano S, Sugiyama M, Hama $H$, Watakabe A, Hasegawa $N$, Kuchimaru T, Tanaka KZ, Takahashi M, Ishida Y, Hata J, Shimozono S. Single-cell bioluminescence imaging of deep tissue in freely moving animals. Science. 2018; 359 (6378): 935-9.
11. Branchini BR, Southworth TL, Fontaine DM, Kohrt D, Florentine CM, Grossel MJ. A Firefly luciferase dual color bioluminescence reporter assay using two substrates to simultaneously monitor two gene expression events. Sci Rep. 2018; 8 (1): 5990.

12. Kim SB, Nishihara R, Citterio D, Suzuki K. Fabrication of a new lineage of artificial luciferases from natural luciferase pools. ACS Comb Sci. 2017; 19 (9): 594-9.

13. Nishihara R, Hoshino E, Kakudate $Y$, Kishigami S, Iwasawa N, Sasaki SI, Nakajima T, Sato M, Nishiyama S, Citterio D, Suzuki K. Azide-and dye-conjugated coelenterazine analogues for a multiplex molecular imaging platform. Bioconj Chem. 2018; 29 (6): 1922-31.

14. Rathbun CM, Porterfield WB, Jones KA, Sagoe MJ, Reyes MR, Hua CT, Prescher JA. Parallel screening for rapid identification of orthogonal bioluminescent tools. ACS Cent Sci. 2017; 3 (12): 1254-61.

15. Hiblot J, Yu Q, Sabbadini MD, Reymond L, Xue L, Schena A, Sallin O, Hill N, Griss R, Johnsson K. Luciferases with tunable emission wavelengths. Angew Chem. 2017; 129 (46): 14748-52.

16. Rumyantsev KA, Turoverov KK, Verkhusha W. Near-infrared bioluminescent proteins for two-color multimodal imaging. Sci Rep. 2016; (6): 36588.

17. Kotlobay A, Sarkisyan KS, Mokrushina Yu, Marcet-Houben M, Serebrovskaya EO, Markina NM, et al. A genetically encodable bioluminescent system from fungi. Proc Natl Acad Sci USA. 2018; in press.

18. Kaskova ZM, Dörr FA, Petushkov VN, Purtov KV, Tsarkova AS, Rodionova NS, et al. Mechanism and color modulation of fungal bioluminescence. Sci Adv. 2017; 3 (4): e1602847.

19. Schultz DT, Kotlobay AA, Ziganshin R, Bannikov A, Markina NM, Chepurnyh TV, et al. Luciferase of the Japanese syllid polychaete Odontosyllis umdecimdonta. Biochem Biophys Res Comm. 2018; (502): 318-23.

\section{References}

1. Cevenini L, Camarda G, Michelini E, Siciliano G, Calabretta MM, Bona R, Kumar TS, Cara A, Branchini BR, Fidock DA, Roda A. Multicolor bioluminescence boosts malaria research: quantitative dual-color assay and single-cell imaging in Plasmodium falciparum parasites. Anal Chem. 2014; 15; 86 (17): 8814-21.

2. Chudakov DM, Matz MV, Lukyanov S, Lukyanov KA. Fluorescent proteins and their applications in imaging living cells and tissues. Physiol Rev. 2010 Jul; 90 (3): 1103-63.

3. Kaskova ZM, Tsarkova AS, Yampolsky IV. 1001 lights: luciferins, luciferases, their mechanisms of action and applications in chemical analysis, biology and medicine. Chem Soc Rev. 2016; 45 (21): 6048-77.

4. Nakajima Y, Ohmiya Y. Bioluminescence assays: multicolor luciferase assay, secreted luciferase assay and imaging luciferase assay. Expert Opin Drug Discov. 2010; 5 (9): 835-49.

5. Yao Z, Zhang BS, Prescher JA. Advances in bioluminescence imaging: new probes from old recipes. Curr Opin Chem Biol. 2018; 45: 148-56.

6. Shimomura O. Bioluminescence: chemical principles and methods. Singapore: World Scientific; 2012.

7. Hall MP, Unch J, Binkowski BF, Valley MP, Butler BL, Wood MG, Otto P, Zimmerman K, Vidugiris G, Machleidt T, Robers MB. Engineered luciferase reporter from a deep sea shrimp utilizing a novel imidazopyrazinone substrate. ACS Chem Biol. 2012; 7 (11): 1848-57.

8. Rajendran M, Dane E, Conley J, Tantama M. Imaging adenosine triphosphate (ATP). Biol Bull. 2016; 231 (1): 73-84.

9. Kuchimaru T, Iwano S, Kiyama M, Mitsumata S, Kadonosono T, Niwa H, Maki S, Kizaka-Kondoh S. A luciferin analogue generating near-infrared bioluminescence achieves highly sensitive deeptissue imaging. Nat Commun. 2016; 7: 11856. 
10. Iwano S, Sugiyama M, Hama H, Watakabe A, Hasegawa N, Kuchimaru T, Tanaka KZ, Takahashi M, Ishida Y, Hata J, Shimozono S. Single-cell bioluminescence imaging of deep tissue in freely moving animals. Science. 2018; 359 (6378): 935-9.

11. Branchini BR, Southworth TL, Fontaine DM, Kohrt D, Florentine CM, Grossel MJ. A Firefly luciferase dual color bioluminescence reporter assay using two substrates to simultaneously monitor two gene expression events. Sci Rep. 2018; 8 (1): 5990.

12. Kim SB, Nishihara R, Citterio D, Suzuki K. Fabrication of a new lineage of artificial luciferases from natural luciferase pools. ACS Comb Sci. 2017; 19 (9): 594-9.

13. Nishihara R, Hoshino E, Kakudate $Y$, Kishigami S, Iwasawa N, Sasaki SI, Nakajima T, Sato M, Nishiyama S, Citterio D, Suzuki K. Azide-and dye-conjugated coelenterazine analogues for a multiplex molecular imaging platform. Bioconj Chem. 2018; 29 (6): 1922-31.

14. Rathbun CM, Porterfield WB, Jones KA, Sagoe MJ, Reyes MR, Hua CT, Prescher JA. Parallel screening for rapid identification of orthogonal bioluminescent tools. ACS Cent Sci. 2017; 3 (12) 1254-61.
15. Hiblot J, Yu Q, Sabbadini MD, Reymond L, Xue L, Schena A, Sallin O, Hill N, Griss R, Johnsson K. Luciferases with tunable emission wavelengths. Angew Chem. 2017; 129 (46): 14748-52.

16. Rumyantsev KA, Turoverov KK, Verkhusha W. Near-infrared bioluminescent proteins for two-color multimodal imaging. Sci Rep. 2016; (6): 36588.

17. Kotlobay A, Sarkisyan KS, Mokrushina Yu, Marcet-Houben M, Serebrovskaya EO, Markina NM, et al. A genetically encodable bioluminescent system from fungi. Proc Natl Acad Sci USA. 2018; in press.

18. Kaskova ZM, Dörr FA, Petushkov VN, Purtov KV, Tsarkova AS, Rodionova NS, et al. Mechanism and color modulation of fungal bioluminescence. Sci Adv. 2017; 3 (4): e1602847.

19. Schultz DT, Kotlobay AA, Ziganshin R, Bannikov A, Markina NM, Chepurnyh TV, et al. Luciferase of the Japanese syllid polychaete Odontosyllis umdecimdonta. Biochem Biophys Res Comm. 2018; (502): 318-23. 